\title{
Ruas, quartos, janelas Manuel Bandeira espia
}

\author{
Giovanna Dealtry
}

\section{SciELO Books / SciELO Livros / SciELO Libros}

DEALTRY, G. Ruas, quartos, janelas: Manuel Bandeira espia. In: WERKEMA, A.S., ROCHA, F.C.D., and OLIVEIRA, L.D., eds. Literatura brasileira em foco VIII: outras formas de escrita [online]. Rio de Janeiro: EdUERJ, 2018, pp. 123-135. ISBN 978-85-7511-487-2. https://doi.org/10.7476/9788575114872.0008.

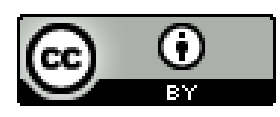

All the contents of this work, except where otherwise noted, is licensed under a Creative Commons Attribution 4.0 International license.

Todo o conteúdo deste trabalho, exceto quando houver ressalva, é publicado sob a licença Creative Commons Atribição $\underline{4.0}$.

Todo el contenido de esta obra, excepto donde se indique lo contrario, está bajo licencia de la licencia $\underline{\text { Creative Commons }}$ $\underline{\text { Reconocimento 4.0. }}$ 
Giovanna Dealtry

Ruas, quartos, janelas: Manuel Bandeira espia 
Começo esta reflexão sobre Manuel Bandeira e o Modernismo chamando à cena um de seus melhores amigos, o poeta e escritor Ribeiro Couto. Hoje, praticamente esquecido, Couto teve um papel de destaque na transição para o Modernismo, em especial, quando se muda de São Paulo para o Rio de Janeiro, e trava contato com Manuel Bandeira. Em 1920, o poeta pernambucano muda-se para o Curvelo, em Santa Teresa, onde Couto já morava. Como o próprio Bandeira relata em sua biografia literária, Itinerário de Pasárgada, "foi por intermédio dele que tomei contato com a nova geração literária do Rio e de São Paulo, aqui com Ronald de Carvalho, Álvaro Moreyra, Di Cavalcanti, em São Paulo, com os dois Andrades [...].” (Bandeira, 2012, p. 83). Em seguida, Bandeira declara que, quando Mário de Andrade esteve no Rio para ler na casa de Ronald de Carvalho e na de Olegário Mariano a inédita Paulicéia Desvairada, "eu já estava bem preparado para receber de boa cara os desvairismos de Mário, porque Ribeiro Couto, era um 'grande farejador de novidades' da Itália, Espanha e Hispano-América”.

O círculo de boêmios intelectuais seria ainda acrescido por nomes como Jaime Ovalle, Sérgio Buarque de Hollanda, Rodrigo Mello Franco de Andrade, Dante Milano, Geraldo Barrosos do Ama- 
ral, entre outros. Cada um desses homens, a seu modo, estava propondo caminhos para o Brasil modernista. Nesse sentido, o pensar modernista carioca passava invariavelmente pelo caminho das ruas e da cultura popular.

O conto "Endereço de Tia Ciata" (1935), de Ribeiro Couto, pode ser lido como um registro desse momento peculiar do modernismo carioca quando a tradição literária se vê invadida por aspectos e personagens da cultura popular que irão subverter a ordem e mudar os parâmetros da composição poética. Dominam o conto a musicalidade e a temática afro-brasileira de alguns poemas de Bandeira colocados em tensão constante com a tradição conservadora. O personagem central é José Elezeário Gomes, crítico literário e funcionário público. Em relação à sua primeira atividade, tem posição categórica: “- Sou pelas Boas Tradições do Verso”. Imagine-se, pois, o espanto quando José Elezeário recebe um exemplar autografado do livro de Manuel Bandeira, Libertinagem, publicado em 1930.

Trancou na gaveta o livro secreto, mas não conseguiu escapar ao atordoamento provocado por aqueles 'pseudos-versos'. Até que um dia, como que emperrando em um obstáculo sub-consciente, passou a repetir:

- Sambas de tia Ciata,

Cadê mais a tia Ciata,

Talvez em Dona Clara meu branco,

Ensaiando cheganças p’ra o Natal (Couto, 1935, p.

174).

No poema "Mangue", Bandeira traz para a poesia o cotidiano das ruas esquecidas do Rio, da mesma forma em que se nutre das formas, ritmos, musicalidades próprias ao universo afro-brasileiro. José Elezeário torna-se então obcecado pelos versos e pela própria 
Tia Ciata. Libertinagem o havia enfeitiçado. "Sobretudo aquele pseudo-poema da página 31, e sobretudo a misteriosa atmosfera criada pelo dito pseudo-poema" (p.172).

O feitiço dá-se através da fala, não mais da fala primeira do feiticeiro negro, mas do feiticeiro branco Bandeira contaminado em definitivo pela junção entre palavra cantada e música, própria às liturgias de matrizes africanas. Diante do encanto nem branco nem negro somente, mas também branco e também negro, o defensor das boas tradições do verso teima em proteger seus princípios que até então pareciam inabaláveis. O "outro", representado por Tia Ciata, o toma duplamente: como revolução poética e forte presença musical. O corpo do pobre José Elezeário não suporta essa invasão.

José Elezeário torna-se "cavalo"1 de Bandeira, ou de Tia Ciata falando por Bandeira. $\mathrm{O}$ funcionário público transforma os versos em assobios, cantoria, música de feitiçaria e passa a perseguir esse fantasma de mulher, emblema da cultura afro-brasileira. Inúteis tentativas do crítico de compreender e delimitar os versos de Bandeira ou encontrar o endereço de Tia Ciata. Encontrar tais respostas onde mora Tia Ciata?, o que são aqueles versos? - implicaria uma redefinição do próprio lugar de fala do crítico literário tradicionalista.

Nesta nova ordem, construída pela modernidade, o intelectual passa a valorizar compositores populares, integrantes dos candomblés, marginais, como narradores de suas próprias contranarrativas não oficiais. Ou se rompe com a tradição dos bons versos e da boa cultura, ou se sucumbe diante do inevitável.

\footnotetext{
1 O termo "cavalo" aplica-se aos sujeitos que durante os ritos do Candomblé incorporam os orixás.
} 
Ribeiro Couto (1935, p. 180) traça de maneira fatalista o destino de homens como José Elezeário Gomes.

À distância, o Maravilhoso fizera efeito. Tia Ciata e os demais fluídos líricos perseguiam José Elezeário Gomes. O Defensor Perpétuo das Boas Tradições do Verso consumia-se, cada dia um pouco, com todos os seus Pontos de Vista. Uma noite, sangue de José Elezeário Gomes virou água. D. Candoquinhas foi ver, estava morto.

Tia Ciata, "Manu" Bandeira, a fala errada do povo, o canto africano, "os novos fluídos líricos" modernistas terminam por suplantar a defesa conservadora da poesia. Como na "Macumba do Pai Zusé", também de Libertinagem, o Rio de Janeiro se contamina apesar das distâncias e das diferenças sociais. Mandinga do Encantado e de Tia Ciata invadindo os territórios de resistência da cidade.

$\mathrm{Na}$ macumba do Encantado

Nego véio pai de santo fez mandinga

No palacete de Botafogo

Sangue de branca virou água

Foram vê estava morta!

Em Itinerário de Pasárgada, Bandeira afirma que Libertinagem teria nascido da convivência quase diária com ilustres boêmios como Jaime Ovale, Dante Milano, Osvaldo Costa e Geraldo Barroso do Amaral. Poemas como "Mangue", "Macumba do Pai Zusé", "Noturno da Lapa" e "Na boca" "seriam resultado da convivência do grupo entre si e da comunhão com a cidade". O antológico "Noturno na Lapa", ainda segundo o poeta, foi aproveitado de um caso vivenciado por Ovale quando este morava na Rua Conde Lage.

Nos poemas de Bandeira, os lugares nomeados do Rio de Janeiro são, simultaneamente, tratados como espaços geográficos, remetendo o leitor ao presente da cidade ocupada pelas camadas marginalizadas, e também narrativizados, corroendo as fronteiras 
de classe, raça e cultura, transformando a poesia modernista em território livre de idas e vindas, entre o centro e as margens.

Na poesia de Bandeira vemos a intersecção entre bairros, ruas, terreiros de candomblé, cafés, em suma, a rua, e as próprias moradas de Bandeira na cidade. A rua torna-se campo de observação e aprendizagem, ainda mais quando consideramos a importância do olhar e da escuta na poesia do poeta.

A rua do Curvelo ensinou-me muitas coisas. Couto foi avisada testemunha disso e sabe que o elemento de humilde quotidiano que começou a se fazer sentir desde então em minha poesia não resultava de nenhuma intenção modernista. Resultou, muito simplesmente, do ambiente do Morro do Curvelo. Disse-o Couto melhor do que eu mesmo poderia explicar agora: 'Das vossas amplas janelas, tanto as do lado da rua em que brincavam crianças, como as do lado da ribanceira, com cantigas de mulheres pobres lavando roupa nas tinas de barrela, começastes a ver muitas coisas. $\mathrm{O}$ morro do Curvelo, em seu devido tempo, trouxe-vos aquilo que a leitura dos grandes livros da humanidade não pode substituir: a rua.' (Bandeira, 2012, p. 82).

Se Libertinagem, composto na sua totalidade no Curvelo, assim como Ritmo Dissoluto e Crônicas da província do Brasil, surge como o livro que marca a maturidade modernista de Bandeira, seja pela adoção da diversidade rítmica, dos versos livres, e, em especial, pela inclusão da cidade polifônica à matéria poética, é também certo afirmar que o espaço da rua já estava presente na formação do poeta desde a infância, quando este se dá conta que "A vida não me chegava pelos jornais nem pelos livros/Vinha da boca do povo na língua errada do povo/Língua certa do povo/Porque ele é que fala gostoso o português do Brasil/Ao passo que nós/O que fazemos/É macaquear/A sintaxe lusíada [...]" (Evocação ao Recife - 1925). O erro, tantas vezes valorizado pelo Modernismo, assim como a infância, traduz-se aqui pela proximidade com o povo e o falar das ruas, em semelhança ao poema "Na rua do sabão" (Ritmo dissoluto - 1924), 
que se inicia de forma abrupta, como se o canto das crianças invadisse o poema ou o pensamento do poeta. "Cai cai balão/Cai cai balão/ Na rua do Sabão!"

Vemos nas obras escritas no Curvelo, no bairro de Santa Teresa, o estabelecimento definitivo do vínculo entre rua e linguagem que encontra no olhar e na poesia de Bandeira sua mediação. É desse lugar de mediador - entre a herança letrada de base europeia e a sedução imperativa do quotidiano humilde das ruas - que Bandeira nos fala. Como a mandinga do Encantado, a poética bandeiriana religa, contamina, os espaços físicos e simbólicos da cidade, a partir da cultura, em especial, das classes populares.

Nos anos 1930, Bandeira colabora assiduamente para revistas literárias e a grande imprensa. No volume Crônicas da província do Brasil, de 1937, estão reunidos textos publicados nos jornais A província, de Recife, Diário Nacional, de São Paulo, e O Estado de Minas, de Belo Horizonte, além das revistas Souza Cruz e Boletim de Ariel.

Encontramos nestes escritos um "provinciano" que, à semelhança da caravana paulista que segue com Blaise Cendras às cidades históricas de Minas Gerais, também irá descobrir o Brasil através das viagens. Como observa Francisco de Assis Barbosa, se Bandeira já conhecera inúmeras cidades brasileiras em busca do clima apropriado aos seus problemas de saúde, "foi com o modernismo que passou a sentir o Brasil" e sua "iniciação nativista” é acompanhada e guiada de perto por Mário de Andrade.

Assim, em carta de 02 de fevereiro de 1928 escrita a Mário de Andrade, Bandeira fala dos planos de viagem, ao lado de outro "provinciano", conhecedor do Brasil.

O Gilberto (Freyre) está assanhado pra fazer uma viagem comigo às velhas cidades mineiras que nem eu nem ele conhecemos. É provável que a ideia pegue. Iremos a São João d'El Rei, Ouro Preto, Mariana, Congonhas, Sabará [...] Se você tem algum conselho ou sugestão a fazer me escreva logo, porque 
é possível que partamos a 10 dias mais ou menos (Bandeira, 2006, pp. 242-3).

As viagens de (re)conhecimento pelo Brasil, de Ouro Preto à Bahia, de Recife aos subúrbios do Rio, cumprem não somente o ideário modernista, mas tornam-se vozes na prosa e na poesia de uma experiência direta da realidade brasileira.

Se "a poesia está nos fatos", conforme sentencia Oswald de Andrade, Bandeira traz os fatos estéticos para o espaço da crônica, por meio de um olhar que nunca se mistura completamente ao "outro". O Rio de Janeiro apesar de não ser o centro oficial do modernismo pós22 torna-se território singular em que a vida da metrópole dissolve as fronteiras com o que há de mais "bárbaro e nosso", nas ruas da cidade, diante do poeta. A proximidade, desejada em manifestos, cartas, romances, com o povo brasileiro, suas vozes, corpos, festas, aqui se revela como imposição cotidiana aos artistas do modernismo. Como fica claro na crônica "Sambistas", publicada em Crônicas da Província do Brasil (1936), em que Bandeira (p. 153) recorda o encontro com Sinhô, em 1920. Sinhô viria a morrer dez anos depois.

Quando morreu o afamado Sinhô, escrevi para o Diário Nacional de São Paulo uma crônica em que recordava com saudade alguns traços curiosos da figura do rei do samba carioca. E contei uma cena a que tive o prazer de assistir em casa dos meus amigos Eugênia e Álvaro Moreyra. Foi o caso que numa das extintas deliciosas quintas-feiras em que o casal recebia, apareceu o Sinhô e regalou os convidados não só com a sua conversação como com os seus sambas. Estava mal de voz, tossia muito (era a velha tuberculose que apertava o cerco), mas nenhum de nós teve a menor ideia de atribuir aquela tosse à terrível moléstia e, como era do mais elementar dever, poupar o doente. O que nos desculpa daquela descaridade é que Sinhô para toda gente era uma criatura fabulosa, vivendo no mundo noturno do samba, zona impossível de localizar com precisão - é no Estácio mas bem perto ficam as macumbas do Encantado, mundo onde a impressão que se tem é que ali o pessoal vive de brisa, cura a tosse com 
álcool e desgraça pouca é bobagem. Assim quando Sinhô parava num acesso, ia-se buscar uma boa lambada de Madeira e o fato é que a tosse passava.

Se o corpo real de Sinhô está ali no espaço da casa dos Moreyra, jornalistas e empresários teatrais, com seu samba e sua tosse, a "criatura fabulosa", originário de uma fábula talvez, habita a zona impossível de localizar com precisão, fronteira entre espaços não somente econômicos, mas especialmente culturais, que não é dado ao observador Bandeira compreender. Por isso, o caráter de excentricidade e, talvez, da impossibilidade de existência concreta do Rei do Samba contaminam o relato afastando do teor documental. Por outro lado, ao transformar Sinhô de sambista em personagem literário da cidade e seus costumes, Bandeira distancia-se da cidade concreta e passa a negociar com a imagem inventada do carioca malandro, da cidade ficcionalizada. A fala, do cronista ou do poeta, situa-se nessa interface, ora roçando a aspereza do real, ora distanciando-se do chão das gentes, voltando o olhar para a distância, como o balãozinho que "...foi subindo.../ muito serenamente.../ para muito longe....

Entre o próximo e a distância, o quarto.

Bandeira irá assumir uma voz discursiva própria no Modernismo brasileiro, somando o falar gostoso do povo à evocação de um eu lírico marcado pela fantasmagoria da morte, permanecendo muitas vezes um observador de fronteira, resguardado em seu quarto suspenso no ar, como lembrado em "Última canção do Beco" (Lira dos cinquent'anos):

Vão demolir esta casa

Mas meu quarto vai ficar,

Não como forma imperfeita

Nesse mundo de aparências: 
Vai ficar na eternidade,

Com seus livros, com seus quadros,

Intacto, suspenso no ar!

O quarto é presença constante na obra de Bandeira. O quarto do tísico, o quarto cuja janela se abre sobre o Curvelo, o quarto de onde espia o beco e a estrela da manhã, quarto onde ao admirar os aviões partindo do Santos Dumont aprende a se despedir também, quarto idealizado a ficar pela eternidade em conversa com o amigo Jaime Ovale. Os quartos reais são muitos - no Curvelo, na Morais e Vale, no Castelo - , ao mesmo tornam-se espaços de intimidade, extensão do eu lírico, cujas fronteiras se desfazem diante do abraço com a cidade.

Na visão de Davi Arrigucci, o quarto na poesia de Bandeira adquire estatuto de microcosmo da interioridade lírica, sem nunca, no entanto, confundir-se com uma "torre de marfim" ou mero refúgio das dores existenciais. Torna-se um "espaço de mediação entre a mais funda interioridade lírica e o mundo exterior, onde se processa uma metamorfose essencial do ponto de vista poético" (1990, p. 63).

Na poética bandeiriana não existe a oposição rígida entre casa/ quarto e rua/cidade. Pelo contrário, são territórios intercambiáveis onde o "eu" torna-se objeto do olhar de si mesmo e do outro. Nessa identificação e atração pelo "outro", o olhar de Bandeira transmutase entre o registro lírico, existencial, social.

"O bicho", sempre relembrado pelo forte impacto da denúncia social do homem transmutado em animal pela fome, foi escrito quando o Bandeira morava no condomínio São Miguel, na Av. Beira-Mar, em apartamento de fundos para o pátio interno. Mesmo quarto, apartamento e pátio capturados pela lente de Joaquim Pedro de Andrade, no curta-metragem O poeta do Castelo (1959). No comovente filme, acompanhamos o dia a dia do poeta nas imagens 
mais comezinhas; o poeta compra leite; o poeta faz café; o poeta deita-se na cama, de pijamas, para digitar seus escritos e rir ao telefone. $\mathrm{O}$ poeta abre a janela.

"Poema só para Jaime Ovalle", "Lua Nova”, "Comentário Musical", "A estrela e o anjo" são alguns dos poemas que fazem referência direta ao espaço físico e a centralidade do quarto no cotidiano do poeta. É um "quarto-eu” invadido por memórias, sons, mundo.

O meu quarto de dormir a cavaleiro da entrada da barra.

Entram por ele dentro

Os ares oceânicos, Maresias atlânticas:

São Paulo de Luanda, Figueira da Foz, praias gaélicas da Irlanda...

(Comentário Musical)

Meu novo quarto virado para o nascente:

meu quarto, de novo a cavaleiro da entrada da barra.

Depois de dez anos de pátio.

Volto a tomar conhecimento da aurora.

Volto a banhar meus olhos no mênstruo incruento das madrugadas.

Todas as manhãs o aeroporto em frente me dá lições de partir. (Lua Nova)

Nessa perspectiva, o quarto não é refúgio, lugar de proteção usual dos rumores da rua. Mas ponto de observação - do fora e do dentro - capaz de dimensionar novas experiências. O pátio, o amanhecer que ignora persianas, as lições de partir. A todas, o poeta se abre.

O quarto torna-se lugar do acolhimento da morte e da meditação, mas também fronteira que se faz a espreitar a vida e o desejo. Assim é que o quarto surge como um espaço de mediação entre o "eu" e a descoberta do "outro", do qual o poeta não foge. O quar- 
tos suspensos de Bandeira assim oferecem novas possibilidades de observação do outro, modeladas pelas esquadrias, pelo limite físico imposto pela separação entre a janela e o rés do chão.

"Noturno da Rua da Lapa" abre-se com a sentença fatídica: "A janela estava aberta". Aberta é a poesia de Bandeira que se deixa atravessar e com isso ser atingido pelo inesperado, pelo insólito que interrompe a reflexão do poeta.

"Não posso atinar no que eu fazia: se meditava, se morria de espanto ou se vinha de muito longe." É nesse momento de suspensão que o poeta é interrompido pelo inseto voador que invade o quarto. A vida que chama. A bomba de flit não adianta. O animal fica cada vez maior. Se o poeta volta-se sobre si mesmo, o inseto "implacável" insiste em atingi-lo em sua forma agigantada. Por isso, mesmo o quarto não é um espaço seguro. A janela aberta é a imagem do imponderável, do incontrolável na obra bandeiriana. Por ali se vê o balão subindo, os aviões partindo, deseja-se a lua nova, mas também, via de mão dupla, revela a fragilidade desse suposto espaço de proteção.

É do quarto suspenso no ar da Lapa, recuperado em "Primeira canção do beco" (Estrela da Tarde - 1960), Bandeira recria esse olhar para a rua de prostitutas e travestis.
Teu corpo dúbio, irresoluto,
De intersexual disputadíssima,
Teu corpo, magro não, enxuto,
Lavado, esfregado, batido
Destilado, asséptico, insípido
E perfeitamente inodoro
É o flagelo de minha vida,
Ó esquizoide! ó leptossômica! 
"Dúbio", "intersexual", não deixam dúvidas quanto a se tratar de uma travesti. Da mesma forma, "enxuto", “insípido", "asséptico”, para apontar para um indivíduo bem jovem. Ao menos, um indivíduo cujo corpo ainda não se constitui como de "fêmea" ou "macho", como indica o termo leptossômica, tratado aqui como um sinal de transtorno.

E é justamente esse corpo, "disputadíssimo", que atrai desesperadamente o poeta. Será que podemos ler esse corpo-desejo não bem visto pela sociedade como o enorme inseto de "Noturno da rua da Lapa" a quem a bomba de flint, o desejo de morte, só o faz crescer e tomar todo espaço do quarto?

$\mathrm{Na}$ estrofe final, Bandeira ordena a sua interlocutora:

Póe paradeiro a este tormento!

Liberta-me do atroz recalque!

Vem ao meu quarto desolado

Por estas sombras de convento,

E propicia aos meus sentidos

Atônitos, horrorizados

A folha-morta, o parafuso,

O trauma, o estupor, o decúbito!

O quarto, situado entre lupanares e o Convento das Carmelitas, torna-se por fim espaço do encontro sexual ainda que interdito pelas sombras do recalque, do catolicismo. Mas, talvez, agora, o inseto agigantado de "Noturno da rua da Lapa" tenha partido finalmente do quarto, expulso pela condição atônita do poeta diante do próprio desejo. 


\section{Referências}

ARRIGUCI Jr, Davi. Humildade, paixão e morte. A poesia de Manuel Bandeira. São Paulo: Cia das Letras, 1990.

COUTO, Ribeiro. “Endereço de Tia Ciata”. In Conversa Inocente. Rio de Janeiro: Schmidt, 1935, pp. 171-82.

BANDEIRA, Manuel. Crônicas da província do Brasil. São Paulo: Cosac Naify, 2006.

_. Estrela da Vida Inteira. 20 ed. Rio de Janeiro: Nova Fronteira, 1993.

. Itinerário de Pasárgada. São Paulo: Global, 2012. 